\title{
Changes in forest structure and composition on Changbai Mountain in Northeast China
}

\author{
Limin Dai • Lin Qi • Qingwei Wang • Dongkai Su • \\ Dapao Yu • Yue Wang • Yujing Ye • Shengwei Jiang • \\ Wei Zhao
}

Received: 12 August 2010 / Accepted: 30 December 2010/Published online: 24 June 2011

(C) INRA and Springer Science+Business Media B.V. 2011

\begin{abstract}
- Introduction Long-term ecological studies are essential for understanding the dynamics of natural systems. However, describing long-term dynamics in old-growth forests is often hindered by a lack of archival data.

- Methods In this study, we investigated (1) changes in forest structure and tree species composition and (2) population dynamics of the dominant tree species over a 29-year period (1981-2010) in two old-growth forests with stand ages exceeding 200 years on Changbai Mountain in Northeast China.

- Results Results showed that the stem density of the broad-leaved/conifer mixed forest at $740 \mathrm{~m}$ asl increased slightly from 510 to 515 trees per hectare and the total basal area increased significantly from 36.19 to $46.53 \mathrm{~m}^{2} \mathrm{ha}^{-1}$, suggesting that the forest was still maturing over the study period. However, the coniferous forest at $1,680 \mathrm{~m}$ asl displayed structural changes in the form of a significantly decrease in both stem density and total basal area over the study period. No changes in tree species composition in the two forests were observed.
\end{abstract}

Handling Editor: Guofan Shao

L. Dai $\cdot$ L. Qi $\cdot$ Q. Wang $\cdot$ D. Su $(\bowtie) \cdot$ D. Yu $\cdot$ Y. Wang $\cdot$ Y. Ye $\cdot$

S. Jiang $\cdot$ W. Zhao

Institute of Applied Ecology, Chinese Academy of Sciences,

72 Wenhua Road,

Shenyang 110016, People's Republic of China

e-mail: sudongkai1313@163.com

L. Qi $\cdot$ Q. Wang $\cdot$ Y. Wang $\cdot$ Y. Ye $\cdot$ W. Zhao

Graduate University of Chinese Academy of Sciences,

Beijing 100049, People's Republic of China

D. $\mathrm{Su}$

Jilin Forest Industry Group Limited Liability Company,

Changchun 130021, People's Republic of China
- Discussion Wind was considered to be a frequent natural disturbance affecting the forest structure and dynamics, especially for the coniferous forest at the higher altitude. Dominant tree species in the two forests exploited different biological characteristics in maintaining their respective populations.

Keywords China forestry. Long-term study. Forest dynamics . Wind disturbance Changbai Mountain

\section{Introduction}

Changbai Mountain, 2,691 m asl, a dormant volcano situated on the border between China and North Korea, is the highest mountain in northeast China. Due to the topography and its varying hydrothermal conditions, there is a distinct vertical distribution of vegetation zones on the mountain, in effect presenting a condensed picture of the array of temperate and boreal forests found across northeastern China (Hao et al. 2007).

Previous studies have shown that the composition and distribution of vegetation on Changbai Mountain are closely linked to the history of volcanic eruptions (Zhao 1980; Machida et al. 1987). Between 1000 and 1100 AD, a large scale, highly destructive eruption occurred (Zhao 1980). Since the fifteenth century, four smaller-scale eruptions occurred-in 1413, 1597, 1668, and 1702 (Machida et al. 1987). However, the 1702 eruption almost destroyed the vertical distribution of vegetation on the eastern slope of the mountain (Liu and Wang 1992). After this most recent eruption, some light-demanding tree species such as Olgan larch (Larix olgensis) invaded on bare, burned sites, and developed into forests. ${ }^{14} \mathrm{C}$ analyses of carbonized wood samples indicated that the large area of 
larch forests on the eastern slopes might be the result of secondary regeneration after fires caused by the minor eruptions (Zhao 1980; Liu and Wang 1992).

Research on Changbai Mountain has been conducted since the founding of the People's Republic of China in 1949 . From the early 1950 s to the late 1970 s, researchers focused on the floristic composition and vertical distribution of vegetation zones. Liu (1955) identified a vertical spectrum with four vegetation zones from the base to the top of the mountain: three forest zones and an alpine steppe zone. Huang (1959) also identified a vertical spectrum with four vegetation zones in which the lower three zones were identical to those identified by Liu (1955). However, he found that the alpine steppe zone identified earlier by Liu should more accurately be identified as the alpine tundra zone. This marked the first time that alpine tundra was recognized to occur in northeast China.

After Liu and Huang, other scholars also proposed several divisions for the vegetation zones on the mountain (e.g., Hou 1959; Zhou and Li 1964). During this entire period, timber harvesting was encouraged throughout the region. Research was conducted on forest logging methods and regeneration practices, but study results were often inconsistent and most studies were designed from a short-term, as opposed to a log-term perspective. Studies of the latter kind began in the late 1970s. In 1979, the Research Station of the Changbai Mountain Forest Ecosystem was founded by the Chinese Academy of Sciences. During the subsequent 15 years, ecosystem research at the research station focused on understanding the structure, function, and productivity of the typical forest ecosystems in the region, and major results from this research were published in several volumes of Research of Forest Ecosystem (in Chinese; Shao et al. 1996). Since then studies at the research station have covered a broader range of topics, and international input and cooperation have been strengthened (e.g., Yu et al. 2007; Wang et al. 2009).

Based on Landsat TM imagery and ground surveys, the vegetation on the mountain may be classified into 14 cover types, including eight forest types (Shao et al. 1996). Understanding stand structure and dynamics of the typical forest on Changbai Mountain is one of the central aims of the research station. In this regard, a variety of studies have focused on forest community classification (Wang et al. 1980; Shao et al. 1996; Liu et al. 2002) and forest structure and composition (Liu et al. 1998; Hao et al. 2007; Wang et al. 2009) on the mountain. Some studies have also examined stand dynamics of the typical forest on the mountain. These have generally relied on inventory data collected at a certain point in time (Liu 1997; Chertov et al. 2003), computer modeling (Shao et al. 1994; Chen et al. 2003), tree-ring analysis (Yu et al. 2007), and old-growth studies (Bai et al. 2008). Despite the value of these predictive and reconstructive approaches, research based on long-term forest monitoring remains quite rare.

In this paper, we investigated changes in forest structure and tree species composition from 1981 to 2010 in two permanent plots located in the broad-leaved/conifer mixed forest zone and the coniferous forest zone, respectively, along the north slope of Changbai Mountain. We also analyzed the population dynamics of these plots, with particular attention to the dominant tree species, over this period. This research is intended to enhance our understanding and monitoring capabilities of the dynamics of this distinctive forest ecosystem.

\section{Methods}

\subsection{Study site}

The study site is located in the Changbai Mountain Natural Reserve, northeast China $\left(41^{\circ} 43^{\prime}-42^{\circ} 26^{\prime} \mathrm{N}\right.$, $\left.127^{\circ} 42^{\prime}-128^{\circ} 17^{\prime} \mathrm{E}\right)$. The reserve is about 200,000 ha in size, with an elevation ranging from 740 to $2,691 \mathrm{~m}$. It was established in 1960 and added to the World Biosphere Reserve Network in 1980 as part of the Man and the Biosphere Project. There is little human disturbance in the core zone because Changbai Mountain was protected as the legendary birthplace of the imperial family during the Qing Dynasty (AD 1644-1911) and as the national natural reserve at the beginning of the 1960s (Zhang et al. 2009a).

The reserve is characterized by a mountain climate with a dry and windy spring, a short and rainy summer, a cool and foggy autumn, and long, cold winters. Strong winds are common with a prevailing direction of west-south-west (Yang and $\mathrm{Xu} 2003$ ). The mean annual temperature is $3.3^{\circ} \mathrm{C}$, with a maximum of $32.3^{\circ} \mathrm{C}$ and minimum of $-37.6^{\circ} \mathrm{C}$. The hottest month is August with a mean maximum temperature of $20.5^{\circ} \mathrm{C}$, and the coldest is January, with a mean minimum temperature of $-16.5^{\circ} \mathrm{C}$. Annual precipitation is $671.9 \mathrm{~mm}$ and annual average relative humidity is $66 \%$. A more wet season occurs from June to August, while a relatively dry season occurs from September to May. The mean storm (wind $>17 \mathrm{~m} / \mathrm{s}$ ) frequency increases with altitude, from 30 days/year at $774 \mathrm{~m}$ asl to 267 days/year above 2,623 m asl (Liu 1997).

The vegetation is vertically divided into four zones, the highest one of which is the alpine tundra zone and the lower three of which are forest zones: (1) broad-leaved/conifer mixed forest zone (740-1,100 m), dominated by Korean pine (Pinus koraiensis), Amur linden (Tilia amurensis), Manshurian ash (Fraxinus mandshurica), etc; (2) coniferous forest zone $(1,100-1,700 \mathrm{~m}$ asl), dominated by Yezo spruce (Picea 
jezoensis var. komarovii), Korean pine, Manchurian fir (Abies nephrolepis) and Erman's birch (Betula ermanii); and (3) subalpine birch forest zone (1,700-2,000 m asl), dominated by Erman's birch (Wang et al. 1980). The coniferous and mixed forests below the subalpine birch forest are old-growth forests with closed canopies and stand ages exceeding 200 years (Zhang et al. 2009b).

\subsection{Data collection}

In 1981, two permanent plots, each $100 \times 100 \mathrm{~m}$, were established by the research station along the north slope of Changbai Mountain (Fig. 1). The first was at an altitude of $740 \mathrm{~m}$ (plot 1, 42 $24^{\prime} 07^{\prime \prime} \mathrm{N}, 128^{\circ} 05^{\prime} 45^{\prime \prime} \mathrm{E}$ ) in the broadleaved/conifer mixed forest zone; the second was at

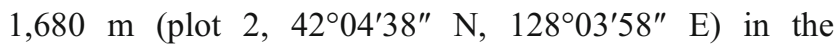
coniferous forest zone. Each plot was named in terms of the three most dominant species by basal area: plot 1broad-leaved Korean pine mixed forest ( $P$. koraiensis $-F$. mandshurica-T. amurensis forest) and plot 2 - spruce-firbirch forest (P. jezoensis var. komarovii-A. nephrolepis-B. ermanii). The topography of the two plots is nearly flat, with a slope of less than $5^{\circ}$. In plot 1 , the density of seedlings of Korean pine and broad-leaved species was numerous, while the sapling $(>1.5 \mathrm{~m}$ in height and $<8 \mathrm{~cm}$ in diameter) layer was occupied by the later; in plot 2 , seedlings of Yezo spruce and Erman's birch were numerous, while the sapling layer was occupied by spruce (Wang et al. 1980).

In 1981, all living trees in each plot with diameters at breast height (DBH; $1.3 \mathrm{~m}$ above the ground) $\geq 8 \mathrm{~cm}$ were identified and measured. In 2010, the two plots were remeasured. Again, only living trees with $\mathrm{DBH} \geq 8 \mathrm{~cm}$ were recorded at this time.

\subsection{Data analysis}

For each inventory, mean DBH, stem density, and basal area were calculated for each individual species. Importance value $(I V=100 \times[$ relative density+relative basal area $] / 2)$ was calculated for each species as a representative description of tree species composition and its change over time (Parker et al. 1985). A Wilcoxon rank sum test was conducted to test for similar shapes of diameter distributions of the stands between the two inventories (Heiri et al. 2009). In this study, the test was conducted to test the difference in the number of trees by $4 \mathrm{~cm}$ diameter classes for all trees and for the three most dominant species in term of basal area within each plot. Using R statistical software (http://www.r-project.org), the exact Wilcoxon test was performed to account for ties in the observations (Streitberg and Rhmel 1986).

Fig. 1 Major vegetation types on Changbai Mountain Natural Reserve, showing the location of the two long-term plots (modified from Wang et al. 2007)

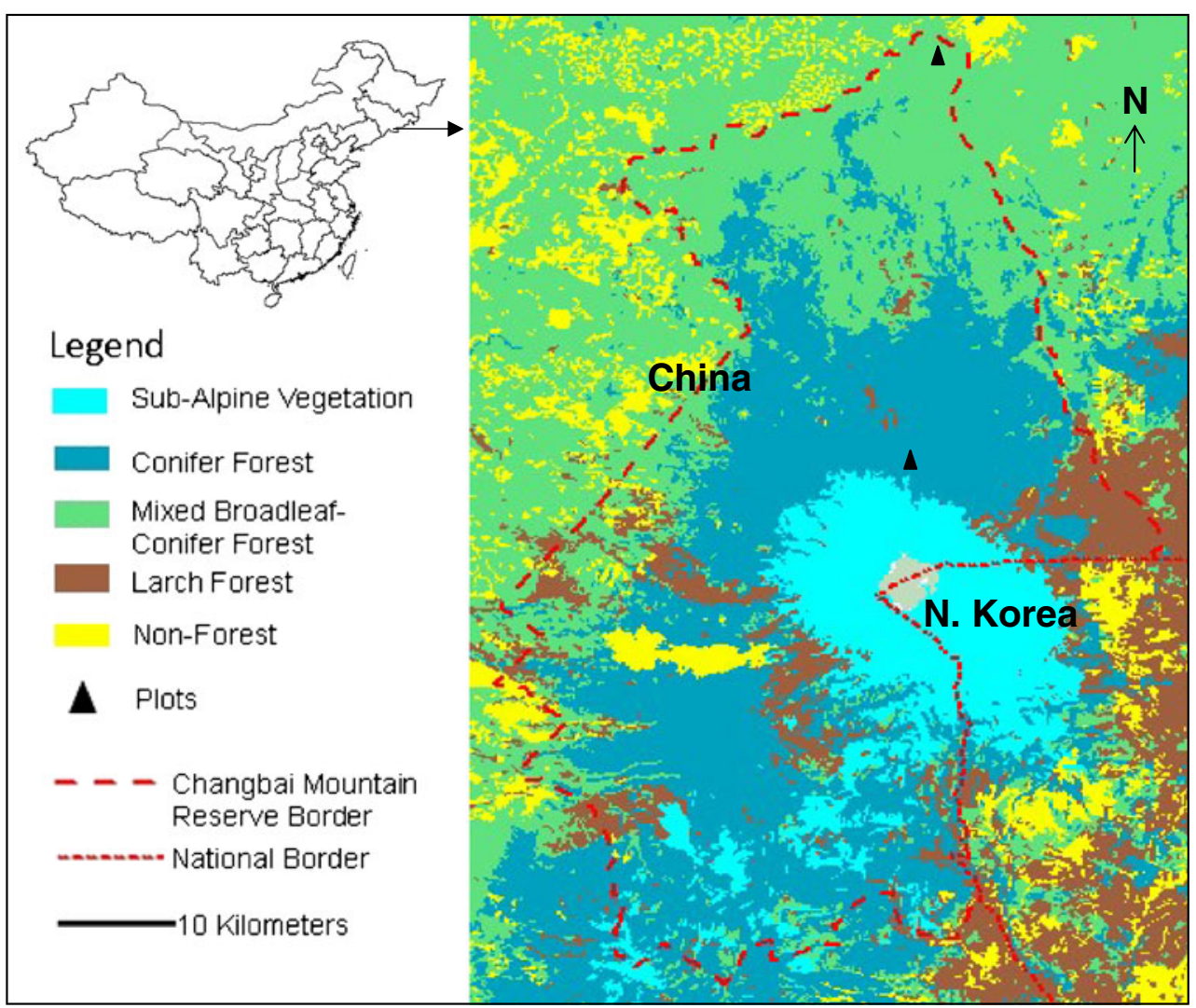




\section{Results}

\subsection{Broad-leaved Korean pine mixed forest}

The first plot was occupied by one conifer species and trees from ten deciduous genera, including five species of maple (Table 1). A total of 15 tree species belonging to ten families were recorded in 1981. Three species-pine, ash, and linden-dominated the stand, with one species of maple also clearly significant. Six species, including one maple, were represented by only one to six trees in the plot.

Korean pine displayed the highest density in the plot by far (150 trees per hectare), and its basal area $\left(10 \mathrm{~m}^{2} / \mathrm{ha}\right)$ was exceeded only by that of Manchurian ash. Along with a mean DBH in the mid-range of all species present, these three factors contributed to Korean pine attaining the highest overall importance value (28.5) of all species in the plot. Manchurian ash accounted for the most basal area $\left(10.95 \mathrm{~m}^{2} / \mathrm{ha}\right)$ and displayed the largest mean DBH $(46.3 \mathrm{~cm})$ in the plot, although it was not nearly as dense as Korean pine, linden, or the most prevalent maple species. Together these factors resulted in the second highest importance value for Manchurian ash (20.8) in 1981.

Two additional species were quite prevalent in plot 1 . Amur linden was the third most dense species in the plot (79 trees per hectare), displaying the third largest basal area $\left(6.6 \mathrm{~m}^{2} / \mathrm{ha}\right)$, and importance value (16.84) behind Koran pine and Manchurian ash. The density of Mono maple (Acer mono) was exceeded only by that of Korean pine, although the former produced only half the basal area of pine and ash. This species of maple had a moderate mean DBH $(20.4 \mathrm{~cm})$ and importance value (16.1). Together these four species of pine, ash, linden, and maple accounted for a combined importance value of 82.3. The 11 remaining species all had densities of 30 trees per hectare or less. Six had densities of less than seven trees per hectare, and three were represented by only a single tree.

A look at the same plot 29 years later revealed the following (Table 1). Overall stem density increased slightly from 510 to 515 trees per hectare. Korean pine still had the highest density, although declining from 150 to 127 trees per hectare. Manshurian ash now was the second most densely distributed species, increasing by $34 \%$ to 106 trees per hectare and surpassing that of Mono maple, whose density declined by $16 \%$ from 1981 to 88 trees per hectare in 2010. As did pine, the density of Manchurian ash decreased slightly from 58 to 50 trees per hectare. Among understory species, Amur maackia (Maackia amurensis) showed the greatest gain in density, increasing almost threefold to 23 trees per hectare. Aspen (Populus davidiana) was the only species represented by a single tree in the earlier inventory to disappear. On an overall basis, nine of the 15 species increased in stem density, but increments for individual species were less than ten trees per hectare.

The total basal area in the plot increased significantly from $36.19 \mathrm{~m}^{2} / \mathrm{ha}^{-1}$ in 1981 to $46.53 \mathrm{~m}^{2} \mathrm{ha}^{-1}$ in 2010 . Increases for 12 species ranged from a low of 0.1 to $4.0 \mathrm{~m}^{2} / \mathrm{ha}$ for Amur linden. Korean pine surpassed Manchurian ash in accounting for the most basal area $\left(12.79 \mathrm{~m}^{2} / \mathrm{ha}\right)$ in 2010 , and these were followed by Amur linden, which had the largest increase in basal area of all species, rising by $60 \%$ to $10.58 \mathrm{~m}^{2} / \mathrm{ha}$. For mono maple, on the other hand, basal area declined by $11 \%$. Mean DBH for all trees increased from $25.9 \mathrm{~cm}$ in 1981 to $28.9 \mathrm{~cm}$ in 2010. Among the 15 tree species originally observed, the mean DBH of 12 increased between 1981 and 2010, but the DBH increment varied considerably, ranging from $0.6 \mathrm{~cm}$ for mono maple to $10.8 \mathrm{~cm}$ for Mongolian oak.

The size class distributions for all trees show a roughly inverse-J curve both in 1981 and 2010 (Fig. 2a). There was no significant difference in size class distributions between study periods (exact Wilcoxon test, $p=0.457$ ). However, the relative abundance of very large trees $(\geq 60 \mathrm{~cm}$ DBH) increased considerably from only $2.2 \%$ of all trees in 1981 to $6.8 \%$ in 2010 .

With respect to the three dominant species, the diameter distribution of Korean pine displayed an approximately normal distribution with peaks at $26 \mathrm{~cm}$ in 1981 and $28 \mathrm{~cm}$ in 2010 (Fig. 2b). Amur linden displayed an irregular distribution in the two inventories, and the density of the medium and larger DBH classes was greater in 2010 than in 1981 (Fig. 2c). The DBH range of Manchurian ash was much broader (maximum size $90 \mathrm{~cm}$ ) than that of pine or linden, displaying an irregular distribution with peaks at $54 \mathrm{~cm}$ in 1981 and $62 \mathrm{~cm}$ in 2010 (Fig. 2d).

On an overall basis, almost three decades after initial measurements, the same four species account for $78 \%$ of total stand importance value, down slightly from 1981. Amur linden displayed the largest increase in value (4.82), almost equaling the combined decrease in value for Korean pine and Manchurian ash. Linden has now edged past the latter as the second highest value (21.66). Amur maackia displayed the most significant gain among understory species in terms of importance value, increasing by 2.0 .

\subsection{Spruce-fir-birch forest}

In the second plot, a total of six tree species belonging to five families were recorded in 1981; this did not change in 2010 (Table 1). Coniferous species include Yezo spruce and Manchurian fir, which dominate the stand, and a few large trees of Olgan larch. Erman's birch is the predominant deciduous species, along with a small number of Mountain ash (Sorbus pohuashanensis) and Ukurundu maple (Acer ukurunduense). 


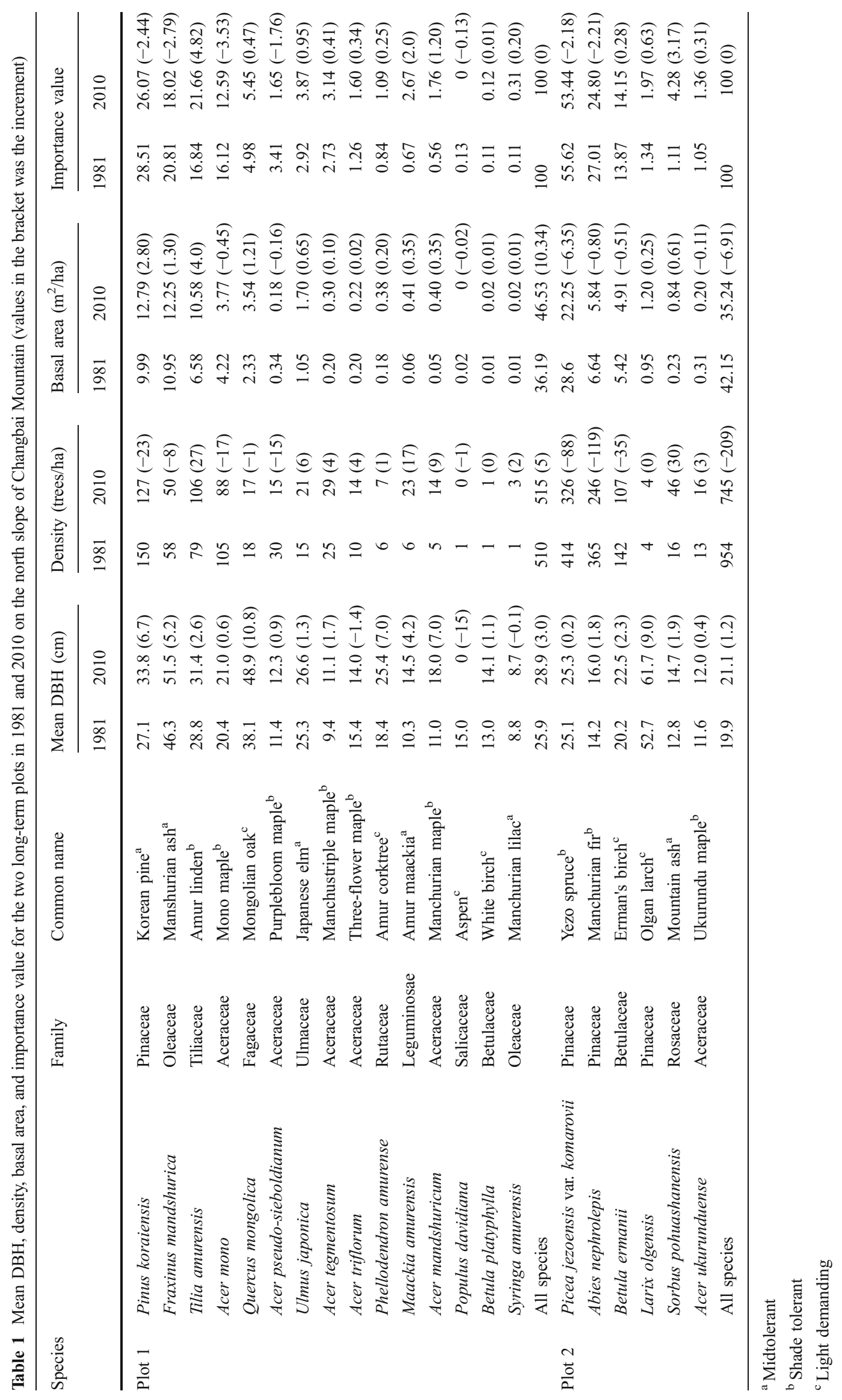


Fig. 2 DBH distributions of living trees for all species and dominant species in two long-term plots in 1981 and 2010. Plot 1: a-d; plot 2: e-h; values on the $x$-axis represent midpoints of DBH classes
Plot 1

Plot 2
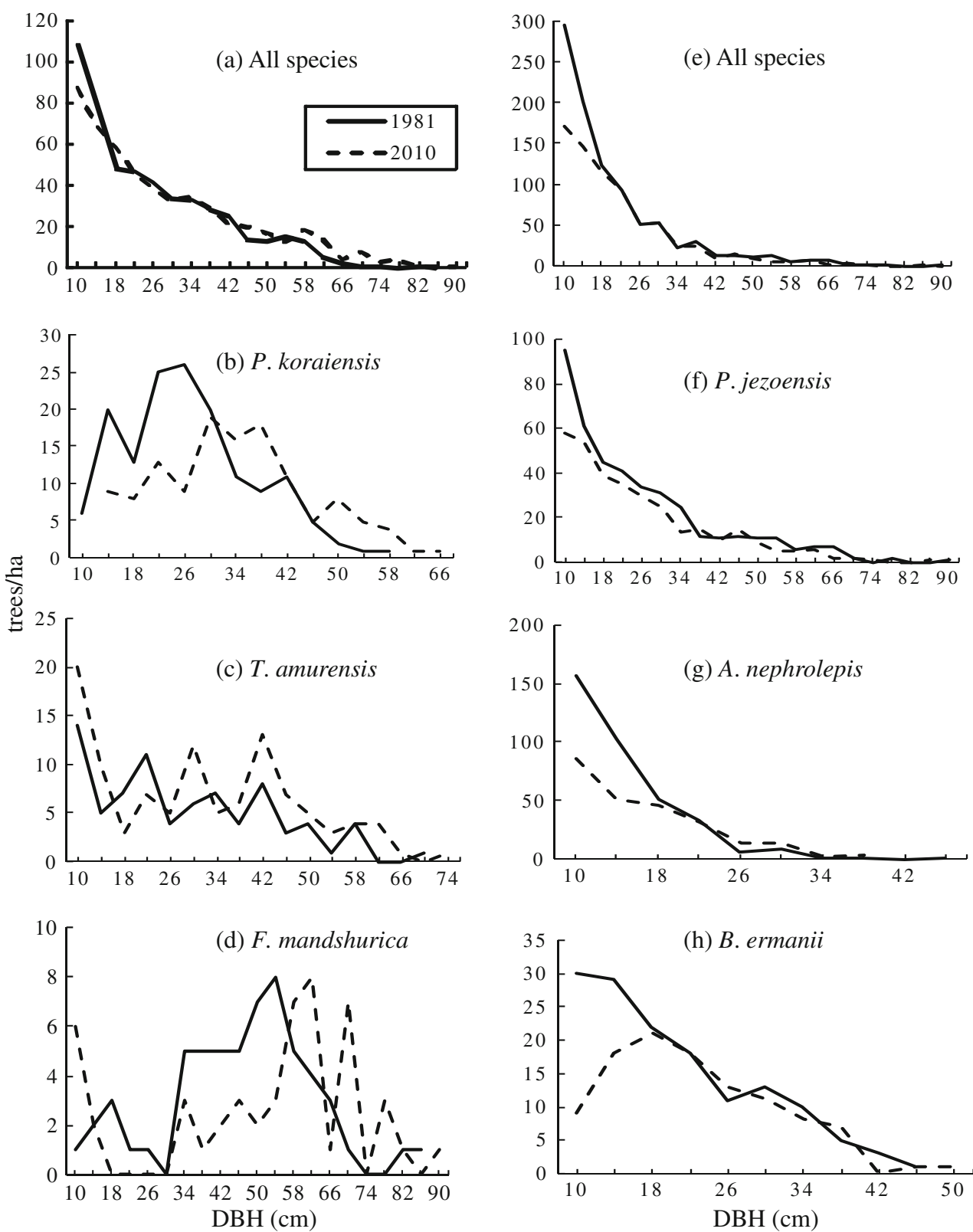

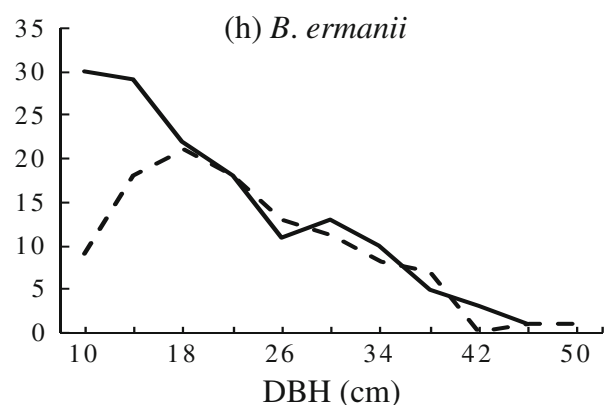

In 1981, the three dominant species of spruce, fir, and birch comprised $95 \%$ of all trees in the plot. Yezo spruce accounted for more than two third of the basal area (28.6 $\left.\mathrm{m}^{2} / \mathrm{ha}\right)$, with Manchurian fir and Erman's birch a distant second and third with $16 \%\left(6.6 \mathrm{~m}^{2} / \mathrm{ha}\right)$ and $13 \%$ $\left(5.4 \mathrm{~m}^{2} / \mathrm{ha}\right)$, respectively. The small number of Olgan larch (four trees per hectare) were by far the most mature in the plot (mean DBH $52.7 \mathrm{~cm}$ ), while spruce, fir, and birch displayed mean DBH's of 25, 20, and $14 \mathrm{~cm}$, respectively.

As is evident in Table 1, stem density for all trees decreased by $22 \%$ from 954 trees per hectare in 1981 to 745 trees per hectare in 2010. Spruce, fir, and birch densities decreased by $21 \%, 32.5 \%$, and $24.5 \%$, respec- tively, while Mountain ash in the understory showed the only substantial increase. Total basal area also declined significantly from 42.15 to $35.24 \mathrm{~m}^{2} / \mathrm{ha}$, with spruce showing the most significant reduction, from 28.60 to $22.25 \mathrm{~m}^{2} /$ ha. Mean DBH for all trees increased from 19.9 to $21.1 \mathrm{~cm}$ over the 29-year study period. The small number of larch trees had the highest increment $(9 \mathrm{~cm})$, while the other species displayed increments of less than $2.3 \mathrm{~cm}$ between the two inventories.

Although the size class distribution for all trees shows a roughly inverse-J curve in both 1981 and 2010 (Fig. 2e), there was a significant difference in size class distributions between study periods (exact Wilcoxon test, $p=0.021$ ). 
Much of this variation resulted from the large difference in the relative abundance of small stems $(<16 \mathrm{~cm} \mathrm{DBH})$, which decreased from 499 trees per hectare in 1981 to 319 trees per hectare in 2010 .

Importance values for the six species in 2010 mirrored those of the earlier inventory. Those for spruce and fir declined slightly to 53.4 and 24.8 , respectively, while only Mountain ash in the understory showed a significant gain $(+3.17)$.

The three dominant species appear to be approaching a quasi-equilibrium status in 2010. Spruce and fir displayed reverse-J diameter distributions in 1981, which leveled off into more horizontal distributions by 2010 (Fig. 2f, g) due to a decline in density of the smaller DBH classes. Erman's birch also displayed a reverse-J diameter distribution in 1981 but evolved into a near-normal distribution with a peak at $16 \mathrm{~cm}$ in 2010 (Fig. 2h).

\section{Discussion}

Landsat TM imagery has revealed the extent of the broadleaved/conifer mixed forest and the coniferous forest as dominant forest cover types on Changbai Mountain, together accounting for about $70 \%$ of the area inside the Changbai Mountain Natural Reserve (Shao et al. 1996). Korean pine was very common in the broad-leaved/conifer mixed forest zone, which occurs at elevations from 700 to $1,000 \mathrm{~m}$ asl on the mountain (Xu et al. 2004). Our results showed that there was a slight increase in plot density and average $\mathrm{DBH}$, along with a more substantial increase in basal area (Table 1), suggesting that the forest was still maturing during the study period. DBH class distribution assumed the shape of an inverse-J curve in both 1981 and 2010 (Fig. 2a), indicating that the forest has consistently maintained a size class distribution typical of an unevenage mixed forest over the past 29 years. DBH class distribution did not differ significantly between the two study periods (exact Wilcoxon test, $p=0.457$ ), suggesting that the tree community has been structurally stable over the course of the study. Density and basal area measurements revealed that Korean pine, Manshurian ash, Amur linden, and Mono maple were the dominant species in 1981, and this was also the case in 2010. The fact that seven of the eight tree species with highest importance value in 1981 remained in the top 8 in 2010 supports the composition of the forest had little changed over the past three decades.

The coniferous forest zone, distributed mainly from 1,100 to $1,700 \mathrm{~m}$ asl on the mountain, accounts for nearly half of the entire reserve (Liu et al. 2002). The spruce-firbirch forest is located in the upper portion of this zone below the subalpine birch forest at elevations ranging from
1,500 to $1,700 \mathrm{~m}$ asl (Xu et al. 2004). Our results showed that both the density and total basal area of plot 2 decreased significantly from 1981 to 2010 (Table 1), suggesting that the forest has declined over the past three decades. Although size classes distributions of all trees displayed an inverse-J shape in both 1981 and 2010 (Fig. 2e), they differed significantly between the two measurements (exact Wilcoxon test, $p=0.021$ ), suggesting that the tree community underwent structural changes over the course of the study period. Although spruce, fir, and birch decreased in stem density and basal area between 1981 and 2010, these three species were still dominant in the forest, with combined stem densities and basal area accounting for $91.1 \%$ and $93.6 \%$, respectively, of the total in 2010 . In term of importance value, no significant changes occurred for these three species. On an overall basis, therefore, the composition of the forest changed little over the past three decades.

Recognizing that the major vegetation within the reserve has experienced approximately 1,000 years of natural succession following the last major volcano eruption (Shao et al. 1996), forest dynamics on the mountain have been affected by another external disturbance factor-wind (Chen and Xu 1991; Shao et al. 1996; Liu 1997). Wind can greatly influence the structure and dynamics of many forests, such as old-growth temperate forests in central Europe (Nagel et al. 2006) and boreal forests in North America (Woods 2004; Bouchard et al. 2009). Wind creates gaps that provide opportunities for the establishment of pioneer species as well as increasing light intensity and stimulating release of other resources for understory tree and seedling growth. In the old-growth forests, gap formation via mortality of individual or small groups of canopy trees is often noted as the dominant process driving forest dynamics (Liu 1997; Nagel et al. 2006).

At the same time, different tree species have different biological characteristics such as shade tolerance, $r$ and $K$ growth strategies, etc., affecting the self-maintenance of a population. For example, Korean pine, a midtolerant species with a type of $K$ growth strategy which produces fewer, high-quality offspring that will survive better, is characterized by distinctive biological characteristics. Seedlings require weak sunlight and can survive under dense canopies, while young trees need strong sunlight for growth (Li et al. 1988). Since the closed canopy does not provide high light conditions, few saplings or young trees can be found in old-growth forests ( $\mathrm{Li}$ and $\mathrm{Zhu} 1990 ; \mathrm{Li}$ and $\mathrm{Li}$ 2003). However, even though many young seedlings die soon after emergence, the seedling bank is still strong enough to keep the population viable, enabling it to take advantage of eventual gap creation for release and subsequent development into the canopy layer ( $\mathrm{Li}$ and Zhu 1990; Li and Li 2003). 
In our study, Korean pine displayed a normal distribution in both 1981 and 2010. At the same time, the density of smaller DBH classes decreased and larger DBH classes increased (Fig. 2b), indicating that the regeneration under the old-growth forest canopy was very poor. These results are consistent with many previous studies (e.g., $\mathrm{Li}$ and $\mathrm{Zhu}$ 1990; Li and Li 2003).

Manchurian ash is a midtolerant species which, despite a broader DBH distribution, showed a similar trend as Korean pine (Fig. 2d). Amur linden is a shade-tolerant species, and its DBH distribution pattern revealed a steady capacity for regeneration both in 1980 and 2010 (Fig. 2c). Although we did not record mortality from damage by wind, Chen and $\mathrm{Xu}$ (1991) found that only 19 trees in plot 1 died between 1981 and 1990. For seven of theseincluding pine and linden - the cause was uprooting or stem breakage, while $63 \%$ of snags were pine and ash. These results suggest that the effect of wind disturbance on the forest was not strong at the lower altitude, contributing to the population of dominant trees remaining stable during the past three decades.

At the higher altitude, the confer forest is often exposed to strong winds (Liu et al. 1998), and Yezo spruce and Manchurian fir, with their large amount of leaf biomass and shallow rooting depth, are vulnerable to wind disturbance (Li et al. 1981; Liu 1997). In plot 2, the three dominant species decreased significantly in stem density and basal area between 1981 and 2010 (Table 1). Stem density declined for almost all DBH classes for spruce and in the small DBH classes for fir and birch (Fig. 2f-h). These results suggest that Yezo spruce, with a broader DBH class distribution, is more vulnerable to wind disturbance than the other species. Both spruce and fir displayed reverse-J diameter distributions in 1981 and 2010 (Fig. 2f, g), reflecting a typical shade-tolerant characteristic and an ability to regenerate well under a dense closed canopy. Erman's birch, a pioneer species, displayed a reverse-J diameter distribution in 1981 but developed a near-normal distribution in 2010 (Fig. 2h). This was not, however, the result of inadequate regeneration. Rather, it appeared that many small DBH classes for birch were overwhelmed when large spruce or fir trees were downed. Erman's birch can adapt to a wide range of light conditions can grow normally under a heavily closed canopy (Liu et al. 1998). It is also strongly resistant to wind, enabling it to maintain itself in the community and, upon occupying gaps in the canopy, provide conditions conducive for spruce and fir to regenerate (Liu 1997).

The coniferous forest is always disturbed by wind, and gaps are always created. After such a disturbance, pioneer species such as Erman's birch can invade open areas as the forest develops toward a climax condition (Liu et al. 2004). The community dynamics of the coniferous forest was expressed as the following succession sequence: mature phase-gap phase-building phase-mature phase (Liu 1997). Therefore, the condition of plot 2 showed that the forest could be in the earlier stage of "building phase." However, in the coniferous forest zone, the climax of the forest is in fact a mosaic structure, consisting of patches in different stages, with inter-patch transformations shaping the overall pattern (Liu 1997).

Results gathered over several decades and/or longer are important to enhancing our understanding of longterm growth dynamics of natural forests. Such findings also help establish a critical baseline dataset on fundamental forest processes underlying stands which may be managed for a variety of outputs in areas other than natural reserves. It is important to the health of forests in China and elsewhere that such work continues and appropriate methods be applied and refined. In this regard, the following foci for future work are suggested by this study.

This study focused on forests at two elevations on the north slope of Changbai Mountain. Should time and resources be available, it will be worthwhile to examine forest stand dynamics on other slopes as well. The establishment of permanent plots on the east, south, and west slopes could complement those observing on the north slope. Climatic and topographical conditions will undoubtedly create a different underlying dynamic that in turn will be reflected in the basic data on forest characteristics. At present, for example, the distribution and importance of Olgan larch is much more extensive on the eastern, as opposed to the northern side of the mountain. For this study, the availability of longer-term data for the north slope of the mountain dictated a focus on that part of the forest ecosystem.

In addition, more research on wind dynamics in forested settings would be welcome. The inference that wind exerted a dominating influence on forest stand composition and structure in the coniferous forest at higher elevations seems warranted by data in this study, but direct supporting data would be even more convincing. Moreover, when thinking of the ever-growing need for research on global climate change, in this case with a particular emphasis on its potential effects on forest zonal patterns, structure, and composition, it would be helpful to include wind as a component of such studies.

Acknowledgments This research was financially supported by the National Natural Science Foundation of China (40873067 and 30800139), the International Partnership Program for Innovation Team and visiting Professorship for Senior International Scientists of the Chinese Academy of Sciences, and the National Forestry Public Welfare Program of China (201104070). We would like to thank Dr. Bernard J. Lewis for editing assistance. We would also thank the invaluable help of the reviewers to improve the manuscript. 


\section{References}

Bai F, Sang W, Li G, Liu R, Chen L, Wang K (2008) Long-term protection effects of national reserve to forest vegetation in 4 decades: biodiversity change analysis of major forest types in Changbai Mountain Nature Reserve, China. Science in China series C: Life Sciences 51:948-958

Bouchard M, Pothier D, Ruel JC (2009) Stand-replacing windthrow in the boreal forests of eastern Quebec. Can J For Res 39:481-487

Chen H, Xu Z (1991) Preliminary study of tree death of Korean pine deciduous mixed forest of Changbai Mountain. Chin J Appl Ecol 2:89-91

Chen X, Li B, Lin Z (2003) The acceleration of succession for the restoration of the mixed-broadleaved Korean pine forests in Northeast China. For Ecol Manage 177:503-514

Chertov O, Komarov A, Kolstrm M, Pitknen S, Strandman H, Zudin S, Kellomki S (2003) Modelling the long-term dynamics of populations and communities of trees in boreal forests based on competition for light and nitrogen. For Ecol Manage 176:355-369

Hao Z, Zhang J, Song B, Ye J, Li B (2007) Vertical structure and spatial associations of dominant tree species in an old-growth temperate forest. For Ecol Manage 252:1-11

Heiri C, Wolf A, Rohrer L, Bugmann H (2009) Forty years of natural dynamics in Swiss beech forests: structure, composition, and the influence of former management. Ecol Appl 19:1920-1934

Hou Z (1959) Site condition of forest region and regeneration of larch on Changbai Mountain. Scientia Silvae Sinicae 4:261-278

Huang X (1959) Natural landscape on northern slope of Changbai Mountain. Acta Geographica Sinica 25:435-446

Li J, Li J (2003) Regeneration and restoration of broad-leaved Korean pine forests in Lesser Xing'an Mountains of Northeast China. Acta Ecologica Sinica 23:1268-1277

Li J, Zhu N (1990) Population structure of Korean pine and its dynamics. Chinese Journal of Ecology 9:6-10

Li J, Zhan H, Liu C (1988) Study about the regeneration on clear-cuts of broadleaved Korean pine at Xiaoxinanlin. Scientia Silvae Sinicae 24:129-137

Li W, Deng K, Li F (1981) Study on biomass and primary production of main ecosystems in Changbai Mountain. Research of Forest Ecosystem 2:34-50

Liu Q (1997) Structure and dynamics of the subalpine coniferous forest on Changbai Mountain. China Plant Ecol 132:97-105

Liu Q, Kondoh A, Takeuchi N (1998) The forest vegetation and its differentiation under disturbance in a temperate mountain. China J For Res 3:111-117

Liu Q, Wang Z (1992) Recent volcanic eruptions and the vegetation history of alpine and subalpine of Changbai Mountain. Research of Forest Ecosystem 6:57-62

Liu Q, Takamura T, Takeuchi N, Shao G (2002) Mapping of boreal vegetation of a temperate mountain in China by multitemporal Landsat TM imagery. Int J Remote Sens 23:3385-3405

Liu Q, Li X, Hu L (2004) Image analysis and community monitoring on coniferous forest dynamics in Changbai Mountain. Chin J Appl Ecol 15:1113-1120
Liu S (1955) Manual of woody plants of Northeast China. China Science, Beijing

Machida H, Morlwaki H, Arai F (1987) Historical eruptions of the Changbai volcano resulting in large-scale forest devastation (deduced from widespread tephra). In: Hanxi Y, Zhan W, Jeffers JNR, Ward PA (eds) The temperate forest ecosystem. Lavenham, Lavenham, pp 23-26

Nagel TA, Svoboda M, Diaci J (2006) Regeneration patterns after intermediate wind disturbance in an old-growth FagusAbies forest in southeastern Slovenia. For Ecol Manage 226:268-278

Parker GR, Leopold DJ, Eichenberger JK (1985) Tree dynamics in an old-growth, deciduous forest. For Ecol Manage 11:31-57

Shao G, Schall P, Weishampel JF (1994) Dynamic simulations of mixed broadleaved-Pinus koraiensis forests in the Changbaishan Biosphere Reserve of China. For Ecol Manage 70:169-181

Shao G, Zhao G, Zhao S, Shugart HH, Wang S, Schaller J (1996) Forest cover types derived from Landsat Thematic Mapper imagery for Changbai Mountain area of China. Can J For Res 26:206-216

Streitberg B, Rhmel J (1986) Exact distributions for permutation and rank tests: an introduction to some recently published algorithms. Statistical Software Newsletter 12:10-17

Wang Q, Chen G, Dai L, Yu D, Ji L, Tong F, Deng H (2007) Ecosystem healthics - theory and application. Liaoning Science and Technology, Shenyang, 133p

Wang X, Hao Z, Zhang J, Lian J, Li B, Ye J, Yao X (2009) Tree size distributions in an old-growth temperate forest. Oikos 118:25-36

Wang Z, Xu Z, Tan Z, Dai H, Li X (1980) The main forest types and their features of community structure in northern slope of Changbai Mountain. Research of Forest Ecosystem 1:25-42

Woods KD (2004) Intermediate disturbance in a late-successional hemlock-northern hardwood forest. J Ecol 92:464-476

Xu W, He X, Chen W, Liu C (2004) Characteristics and succession rules of vegetation types in Changbai Mountain. Chinese Journal of Ecology 23:162-174

Yang X, Xu M (2003) Biodiversity conservation in Changbai Mountain Biosphere Reserve, northeastern China: status, problem, and strategy. Biodivers Conserv 12:883-903

Yu D, Wang G, Dai L, Wang Q (2007) Dendroclimatic analysis of Betula ermanii forests at their upper limit of distribution in Changbai Mountain, Northeast China. For Ecol Manage 240:105-113

Zhang J, Hao Z, Sun I, Song B, Ye J, Li B, Wang X (2009a) Density dependence on tree survival in an old-growth temperate forest in northeastern China. Ann For Sci 66:1-9

Zhang Y, Xu X, Adams MJ, Wang X (2009b) Can Landsat imagery detect tree line dynamics? Int J Remote Sens 30:1327-1340

Zhao D (1980) The altitudinal distribution belts of vegetation on Changbai Mountain. Research of Forest Ecosystem 1:65-70

Zhou Y, Li J (1964) The characteristics of main vegetation on eastern mountain area in Northeast of China types and their regularities of distribution. Acta Phytoecologica et Geobotanica Sinica 2:190-206 